\title{
ONDARA, SEÑORÍO DEL DUQUE DE GANDÍA, A PRINCIPIOS DEL SIGLO XV
}

\author{
José Hinojosa Montalvo*
}

Entre 1791 y 1793 nuestro ilustre antepasado, el botánico Antonio José Cavanilles, recorrió las tierras del antiguo reino de Valencia, y de su acertada y minuciosa visión del país salió esa obra, ya clásica, que es Observaciones sobre la historia natural, geografía, agricultura, población y frutos del Reyno de Valencia, publicado en Madrid en 1795-1797 y reeditado hasta nuestros días. Cuando pasó por Ondara nos dejó la siguiente descripción:

"Al sur de estos pueblos, en la llanura que hay ántes de llegar á Dénia está Ondara, villa de 300 vecinos, y más allá Pamis, aldea de unos 20. El rio Alberca fertiliza los campos de la villa, que parecen bosques de moreras, y en las áreas se ven maices, trigos, y otras producciones de huerta: el caserío de Ondara es muy decente, mejorado y aumentado en los últimos setenta años. Cógense muy cerca de 6000 libras de seda, 600 cahices de trigo, 400 de maiz, 200 de cebada, 150 de habas, 1200 arrobas de aceyte, 10000 de algarrobas, y 1000 cántaros de vino"11.

Como puede verse se trataba de una economía que se sustentaba en la clásica trilogía mediterránea, con la algarroba como producto más abundante, pero con un cultivo estrella que era la morera, fruto del desarrollo alcanzado por la industria de la seda en Valencia a partir del siglo XV, al que se añadían otros cultivos de origen americano, como el maíz, que dan como resultado una agricultura especulativa, lo que, a su vez, se traduce en un buen caserío, en el que se respiraría cierto bienestar, y en un paisaje agrario bastante diferente de centurias anteriores.

Pero ¿cómo era Ondara hacía cuatrocientos años? Para empezar digamos que no era una villa, sino un $l l o c$, un lugar, es decir, una entidad de población de categoría inferior a aquella, que formaba parte de la malla señorial tejida desde la conquista cristiana en el reino de Valencia. Jaime I, tras la conquista de Denia, comisionó al noble En Carrós el reparto de casas y tierras en la comarca, quedando vinculada la trayectoria histórica de Ondara a la de su cabeza

\footnotetext{
* Universidad de Alicante.

1. A.J. CAVANILLES, Observaciones sobre la historia natural, geografía, agricultura, población y frutos del Reyno de Valencia, Zaragoza, 1958, vol. II, pp. 269-270.
} 
comarcal, la villa de Denia. Ignoramos con precisión cuál fue la trayectoria del señorío, aunque no siempre se mantuvo dentro de la órbita de los duques de Gandía, pues en octubre de 1374 estaba en manos de mosén Bernat de Bonastre, secretario del rey, quien todavía lo conservaba en 1391. A principios del siglo XV, en 1402 era ya de don Alfonso, duque de Gandía, pasando a la muerte de éste, en 1422, como legado suyo, a poder de Hug de Cardona. Así pues, en 1408, fecha de nuestro estudio, se integraba en el ducado gandiense.

La fuente utilizada para reconstruir los trazos de su historia en la fecha precisada, aunque de naturaleza fiscal, puede sernos de gran interés para conocer no sólo la renta feudal, sino también aspectos de la estructura social y económica de los mudéjares -y en menor medida de los cristianos- de Ondara a comienzos del Cuatrocientos. Nos encontramos ante un cabreve -en otra ocasión lo llama cappatró- procedente del Archivo del Reino del Valencia ${ }^{2}$, en el que se anotaron los censos y demás cargas abonadas por los vasallos a su señor, el ya citado duque de Gandía (cappatró dels censals, rendes e altres drets del loch d'Ondara), mientras que una segunda parte forma el Libre de la collecta delds lausmes (sic) de les possessions venudes en lo loch de Ondara, cullites per Abadía Zale, alami del dit loch, l'any mill quatrecents setze, es decir, la tasa percibida por el señor por las ventas de las propiedades mudéjares en 1416. Por último, se incluyen en un par de hojas, al final del cuaderno, las ordenanzas dadas por los prohombres y jurados cristianos, junto con la aljama de Ondara, en el año de 1410. El notario que realizó la labor amanuense fue Ramón Vidal.

\section{ONDARA, UNA POBLACIÓN DE MAYORÍA MUDÉJAR}

Ignoramos cómo se produjo el paso de Ondara al dominio cristiano, pero cabe pensar en unos pactos de capitulación entre el poder real, representado por el poderoso magnate En Carrós, y la aljama local, según los cuales la comunidad seguiría disfrutando de sus leyes, costumbres, prácticas sociales y religiosas a cambio del reconocimiento de la soberanía de Jaime I y el pago de una serie de cargas fiscales o prestaciones de servicios, cuyo contenido ignoramos.

La revuelta de al-Azraq, cuyo escenario principal fueron las comarcas montañosas del norte alicantino, modificó la situación, forzando una intensificación de la repoblación cristiana del territorio para su mejor control, pero con resultados escasos para Ondara. En efecto, en el reparto hecho por el monarca aragonés en 1249 a la comarca del marquesado de Denia pertenecen 13 donaciones de bienes, de las cuales sólo una es para Ondara, de la que ni siquiera sabemos si llegó a hacerse efectiva. Ahora bien, la cifra reseñada tampoco corresponde a la realidad, pues el monarca encargó el reparto de Denia a Ca-

2. A.R.V. Maestre racional, 9618. 
rrós y sus donaciones no fueron recogidas en el Libre del Repartiment, por lo que desconocemos la cuantía real de lo repartido. Respecto a lo repartido, en Ondara se dieron 12 hectáreas de secano, sin que se mencionen viñas, huertos o casas ${ }^{3}$. El objetivo de Jaime I era reforzar el poblamiento cristiano en estas comarcas amenazadas por la sublevación de al-Azraq, y es seguro que esta peligrosidad alejaría por el momento la llegada de colonos, que no se incrementaría hasta la rendición definitiva del caudillo musulmán en 1276.

La población, por tanto, siguió siendo musulmana de forma mayoritaria en Ondara durante mucho tiempo, y de hecho lo fue durante toda la Edad Media, frente a una población cristiana inferior, que se iría instalando desde el último cuarto del siglo XIII en un proceso de colonización que desconocemos. Cuando intentamos aproximarnos a la demografía medieval nos movemos casi siempre en un mar de incertidumbres, debido a la carencia de fuentes y a la falta de precisión estadística, ya que las que conservamos, como la presente, se elaboraron con otra finalidad. Sin embargo, tales carencias no deben ser obstáculo para intentar aproximaciones, lo que puede hacerse combinando la fuente fiscal y su contenido prosopográfico con la reconstrucción de la vida de los individuos y de sus familias ${ }^{4}$. Conocer la población, su estructura, es esencial para analizar un sistema social, aunque en este caso sea básicamente la sociedad mudéjar de Ondara. La falta de documentación seriada nos impedirá, por el momento, establecer líneas de evolución, comparaciones, avances y retrocesos, pero al menos servirá como testimonio de las tendencias demográficas de la localidad a comienzos del siglo XV, en un momento en que, finalizada la guerra de Castilla, la de los dos Pedros, que tantos daños causó en la población y la economía de La Marina, la comarca había iniciado ya su recuperación.

Contamos con dos fuentes para aproximarnos al conocimiento de la población de Ondara en la primera década del Cuatrocientos: el morabatín de 1404 y el besante de 1408. El primero era un gravamen, percibido desde 1267, cada siete años sobre la base impositiva de siete sueldos y abonado por todos aquellos que tuvieran bienes por valor de 105 sueldos. De acuerdo con la nómina conservada para 1404, en Ondara había 30 fuegos de cristianos y 90 de mudéjares, es decir, el triple de musulmanes que de cristianos, cuyos nombres pueden verse en el apéndice final ${ }^{5}$. En 1408 y a partir de la tributación del besante sabemos que el número de casas de musulmanes, como mínimo, era de $95(77,9 \%)$, mientras que las de los cristianos era de $27(22,1 \%)$, ya que ignoramos cuántos eran los que no pagaban el impuesto. No vamos a entrar en cifras

3. R. Ferrer NAVArro, «Repoblación de tierras alicantinas por Jaime I», Anales de la Universidad de Alicante. Historia Medieval, 2, 1983, pp. 33-48.

4. Ante la abundantísima bibliografía sobre demografía medieval remito al lector al último trabajo colectivo: Demografía y sociedad en la España bajomedieval, Zaragoza, Universidad, 2002.

5. M.J. PATERNinA BONO, «Relación de los moros y cristianos sujetos al impuesto del morabatí en "lo loch de Ondara" en 1404», Sharq al-Andalus, 6, Alicante, 1989, pp. 119-127. 
concretas, dado que los demógrafos e historiadores no se ponen de acuerdo a la hora de fijar un coeficiente a aplicar, aunque parece que últimamente se tenía preferencia por el de 4,5 personas por hogar, sin tener en cuenta que se trata de valoraciones para la época moderna y básicamente el mundo urbano, que sería diferente del rural. Aplicando un coeficiente 4 tendríamos 488 personas, mudéjares y cristianos; con el de 4,5 un total de 549 , y con cinco personas por hogar contabilizaríamos 610 para el año 1408, aunque ni el más mínimo dato nos permite conocer la composición familiar de los ondareños.

Lo que sí que se constata es una ligera tendencia alcista de la población, con un ligero aumento en la población mudéjar y un leve descenso de los cristianos, que sigue siendo una minoría dentro de la localidad. Por el pago del besante sabemos que este crecimiento fue debido a la instalación en Ondara de musulmanes procedentes de las morerías vecinas: Mahomat Mundo, del valle de Jalón, y los tres hijos de Coot Abencot, de Pedreguer. La citada cifra se vería incrementada con otros personajes, como la prostituta que ese año se instaló en la localidad para ejercer su profesión. El duque estaba interesado en este aumento de la población mudéjar en sus estados y dio diversos privilegios a los que allí acudieran, y en el caso de Ondara sabemos en concreto que, en fecha que desconocemos, declaró francas las casas que se construyeran de nuevo.

Respecto al origen de algunos de estos pobladores podemos deducirlo a través de sus apellidos, aun cuando ignoremos el momento de su instalación en Ondara: así, Albocayriní sería oriundo de Bocairent; Alvalencí, de Valencia; Alcaspí, de Caspe (?); Almanorquí, de Menorca, o Mayorquí, de Mallorca.

\section{LA RENTA SEÑORIAL}

La exacción señorial tenía como punto de partida las capitulaciones pactadas entre el señor y la aljama mudéjar en el momento de la conquista por Jaime I, pero para Ondara no se ha conservado ningún pacto o carta puebla que nos permita aventurar cuáles fueron estas condiciones. A través del cabreve podemos conocer cuáles eran estas exacciones fiscales a principios del siglo XV, ignorando en qué momento fueron concertadas y sus posibles modificaciones en el tiempo. No hay duda que el origen histórico de los señoríos condicionó la diversidad de las rentas, que en este caso se incluía dentro de la clase feudal, en el más alto estamento social, el baronial. Para conocer la mayor o menor dureza de la explotación señorial en el caso de Ondara, necesitaríamos conocer la renta total producida por todo el territorio señorial y poder compararla además con la de otras localidades, lo que, por el momento, no es posible. En cualquier caso, el análisis y clasificación de la renta debe tener como objetivo intentar aproximarnos a las bases económicas de la empresa señorial y de sus vasallos.

Es un hecho evidente que la renta feudal del duque de Gandía, don Alfonso, en el lugar de Ondara era de naturaleza básicamente agraria, a tenor de los datos que nos proporcionan los libros de administración, aunque esta rea- 
lidad predominante se matiza con otras actividades de los sectores secundario y terciario, que se apuntan en el conjunto de las rentas.

Señalemos que en Ondara, aunque predominaban los establecimientos enfitéuticos, se mantenía la reserva señorial, igual que las prestaciones personales por parte de los vasallos mudéjares. Lo sabemos porque a la hora de desglosar el contenido del besante se dice que cada casa de moro debía trabajar tres jornadas de trabajo para el señor, abonando en su lugar la suma de 1 sueldo y 6 dineros por jornal. Cabe pensar que esta reserva fuera lo que se denomina "l'ort del senyor", arrendado por 200 sueldos anuales.

La racionalización en la explotación del señorío a fines de la Edad Media había hecho que el señor englobara una serie de impuestos personales y de la comunidad en un todo, calificado como "besants e drets de cases dels moros", cuya suma anual era de 15 sueldos por cada casa, pagaderos en Navidad. Su desglose, tal como especifica el cabreve era el siguiente:

- besante, 4 sueldos.

- derecho del horno, 2 sueldos.

— tres jornales, a razón de 1 sueldo y 6 dineros el jornal, sumando en total 4 sueldos y 6 dineros.

- un par de gallinas, por valor de 2 sueldos y 6 dineros.

- dos libras para hilar, 2 sueldos ${ }^{6}$.

En primer lugar hay que citar el besante, contribución específica de los musulmanes, que en el condado de Denia era de 3 sueldos y 4 dineros ${ }^{7}$, igual que en otras comunidades mudéjares del reino, como por ejemplo, Corbera ${ }^{8}$, el valle de Ayora $^{9}$ o Perputxent, como consta en su carta puebla. En algunos casos, como en la cercana Calpe, el conde declaró exentos a los mudéjares en 1404 por un periodo de diez años, con el fin de atraer repobladores y que se produjera la recuperación de la localidad ${ }^{10}$. Lo cierto es que, en comparación con otras localidades del marquesado que abonaban los tres sueldos y medio o incluso estaban exentas, en Ondara cada casa pagaba medio sueldo más por

6. "Seguexen los besants e drets de cases dels moros del dit loch d'Ondara, ço és que cascuna casa de moro paga XV sous en aquesta manera, ço és de dret de besant en diners, IIII sous; item, de dret de forn, II sous; item, per III jornals, a raó de I sou, VI diners lo jorn, IIII sous, VI diners; item, un parell de gallines, II sous, VI diners; item, per II lliures de filaç, II sous, axí que és per tot XV sous per cascuna casa de moro cascuns anys pagadors en la festa de Nadal de nostre Senyor".

7. J. ARGENTE VIDAL, «Un libro de cuentas de las morerías del condado de Denia (1379)», Boletín de la Sociedad Castellonense de Cultura, tomo LXIII, julio-septiembre, 1988, pp. 285-321.

8. E. Guinot i RodrígueZ, «La gestió dels llocs de reialenc: les rendes de la batlia de Corbera (1432-1465)», Economía agraria i Història local, p. 295.

9. M.T. FerRer I MALLOL, «La carta de població dels sarraïns de la Vall d'Aiora (1328)», Sharq alAndalus, Estudios Árabes, 3, Alicante, 1986, pp. 81-94.

10. A.R.V. Maestre racional, 96003. 
estas fechas, lo que indica una mayor capacidad del señor para, en un momento que desconocemos, aumentar la fiscalidad sobre sus vasallos mudéjares, fruto también de una mayor estabilidad social y económica de la aljama, lo que se tradujo en un incremento de la demografía, como ya vimos.

En este apartado el escribano anotó también el pago de casas acensadas desde antiguo, que pagaban 3 ó 4 sueldos; casas y un obrador, abonando sumas variables; casas y tintorería, que pagaron 50 sueldos, la suma más elevada. También se incluyeron las casas de las viudas, que en lugar de los 15 sueldos habituales por casa sólo pagaban 6 sueldos y 9 dineros. En algún caso el señor podía hacer gracia a un particular de abonar sólo medio besante, igual que a las viudas, como fue el caso de Caat Açet Lorp. Los nuevos vasallos gozaban también de un descuento en el besante, y así Mahomat Mundo, del valle de Jalón, "axí com a estrany e per ço com se era feyt vassall del senyor duch", abonó sólo 3 sueldos y 4 dineros, igual que los tres hijos de Coot Abencot, moros de Pedreguer, que se instalaron en Ondara.

El dret del forn habitualmente se incluye entre los monopolios señoriales y presenta numerosas fórmulas de explotación por parte señorial. En Eslida, por ejemplo, era una especie de cabezaje por el que todas las personas mayores de tres años abonaban al señor 8 dineros anuales ${ }^{11}$, mientras que en Cheste se trataba de una cantidad alzada al año, pudiendo los mudéjares usar libremente el horno o arrendarlo. Otra fórmula era la de utilizar el horno a cambio del pago de una cantidad en metálico o en especie ( puya), como en Rivesalbes, que era de treinta panes uno. También estaba muy extendida la fórmula del arrendamiento anual, en conjunto, o por una cantidad diaria, como en Crevillent, lo que hacía que las sumas variaran según los años. En Ondara, el señor para evitarse las fluctuaciones anuales y tener una cantidad segura utilizó el sistema de cobrar una cantidad anual por casa, que fue de dos sueldos, cantidad que triplicaba a la que veíamos en Eslida.

El mayor gravamen lo constituían las prestaciones personales, lo que conocemos como sofras, fruto de la capitulación inicial o modificaciones posteriores, que consistían en tres jornales en las tierras del señor, que se redimían abonando 4 sueldos y 6 dineros, es decir se pagaba medio sueldo más que en el besante. Como término de comparación digamos que Ondara se sitúa en una posición intermedia entre Perputxent, en cuya carta puebla de 1316 se fijaba en cuatro los jornales a prestar por los mudéjares, o la de Catamarruc, en el término de Cocentaina, en 1490, en que fueron dos jornales por heredad los estipulados por el señor.

En reconocimiento de su señorío, el vasallo mudéjar venía obligado a entregar al señor un par de gallinas cada año, lo que constituía el dret de les galli-

11. M. Gual Camarena, «Mudéjares valencianos. Aportaciones para su estudio», Saitabi, VII, Valencia, 1949, p. 86 
nas, percibido en numerario, en la suma de 2 sueldos y medio. Ondara es la localidad en que este derecho presenta una tasa más alta, pues en Elche y Crevillent era de 6 dineros en 1319, en Elda y Novelda de 10 dineros en 1355, mientras que en el mismo condado de Denia era de un sueldo en los valles de Castell, Gallinera, Confrides, Ebo, Guadalest y Tárbena ${ }^{12}$.

Completaban este bloque de rentas abonado por las casas de los mudéjares la obligación que sus vasallos mudéjares tenían de hilar el lino de su cosecha para la casa del señor, que en el valle de Guadalest, por ejemplo, eran dos arrobas, como en Castell o en Tárbena. En Ondara se sustituyó por el pago de dos sueldos por casa.

En conjunto, por los mencionados conceptos la señoría ingresó la suma de 1.328 sueldos, que representaron el 14,57\% del total de la renta percibida en Ondara.

Capítulo destacado era lo que se conocía como censales viejos (censals vells), abonados en la fiesta de Navidad por los mudéjares por las tierras, viñedos y otras posesiones que cultivaban ${ }^{13}$. Su origen es desconocido, pero el calificativo de "vells", habla de su antigüedad. Las cantidades eran variables, desde 6 dineros por la tenencia de una viña a 40 sueldos por la cantarería o 46 sueldos y 10 dineros que la mujer y los hijos de Alí Albocayriní abonaron por viñas, variando en función del tipo de cultivo, su extensión y la calidad de la tierra. Había un predominio total del viñedo frente al campo de cereal en secano ("terres"). En total el señor ingresó ese año la suma de 697 sueldos, 3 dineros, que supusieron el 7,82\% del total de las rentas, prácticamente lo mismo que lo que pagaban las casas de los cristianos de Ondara.

El plato fuerte de la renta señorial lo constituían los 4.000 sueldos que el señor ingresaba anualmente de sus vasallos mudéjares y cristianos por las tierras que tenían acensadas, y que equivalía a una partición de frutos, pagaderos la mitad en la fiesta de San Miguel, en el mes de septiembre, y la otra mitad en el mes de febrero ${ }^{14}$. Correspondía al 43,90\% del total de la renta percibida. Ignoramos la proporción a abonar por cada una de las comunidades ni cuándo se estableció este acuerdo con el duque de Gandía.

Parte importante y característica de la renta señorial siempre fue la derivada de los monopolios señoriales, de uso obligatorio por los vasallos. En Ondara eran arrendados anualmente y ofrecen el siguiente balance:

12. J. Hinojosa Montalvo, «La renta feudal de los mudéjares alicantinos», Señorío y feudalismo en la Península Ibérica, Zaragoza, 1993, p. 117.

13. “Seguexesen los censals vells que los moros del dit loch d'Ondara paguen e són tenguts pagar per alcunes terres e vinyes e altres possessions cascun any en la festa de Nadal de nostre Senyor".

14. "Tota la aljama del dit loch e los christians que tenien terres de parta censaren del dit senyor duch perpetualment totes les terres, vinyes e arbres, de les quals fallen part de fruyts per quatre mil sous cascun any, pagadors la meyta (sic) en la festa de sent Miquel, e l'altra meytat per tot lo febrer". 
- La carnicería del lugar, arrendada por un año a Geme Abenafén, alias Manzano, por 600 sueldos, pagaderos en tres tercios.

- El huerto del señor, que arrendó Berenguer Ortopeda por 200 sueldos.

- El derecho de la melcucha, arrendado por la suma de 27 sueldos y 6 dineros a Azmet Abencaber, de Pedreguer. Es la primera vez que lo encuentro mencionado en un arrendamiento y estaría relacionado o bien con la utilización y aprovechamiento de las colmenas y la miel, actividad doméstica muy arraigada en todas las comunidades mudéjares gracias a la rica flora mediterránea de nuestras tierras, o quizá, más específicamente, con la miel ya elaborada ${ }^{15}$. El derecho de las colmenas (herbatge de les colmenes) se arrendó en los valles de Gallinera y de Ebo, también del duque, el año 1397 por la suma de 5 sueldos y 10 dineros, inferior a la de Ondara; en cambio la aljama mudéjar de Perputxent abonaba por cada colmena 2 dineros y óbolo.

- El derecho de la almaxita (dret de l'almaxita), que se arrendó a Axuix Almaxita, de Orba, por 24 sueldos. Ignoro el significado y contenido de esta exacción, que no he encontrado en otra localidad, aunque no deja de ser curioso que el arrendador lleve el apellido del impuesto.

- El tercio diezmo del carnaje (terç del denme del carnatge), que fue arrendado por Manuel Gençor por la suma de 34 sueldos.

- El tercio diezmo de los trigos y frutos, arrendado por un periodo cuatrienal a la aljama del lugar por la cantidad anual de 325 sueldos.

- El derecho de herbaje de las ovejas (dret d'erbage d'ovelles) nos permite adentrarnos en el mundo de la ganadería de los mudéjares ondarenses, que era muy reducida, a tenor de los datos conservados. En efecto, las rentas ganaderas adoptaban dos formas, el herbatje y el atzaque, permitiendo el primero el disfrute de los pastos del término. Su exacción variaba según localidades, y en Elche o Crevillent se arrendaba anualmente, igual que en el norte de Alicante, y así vemos como en 1379 el de Guadalest fue arrendado por la elevada cantidad de 3.400 sueldos, mientras que en la sierra Aitana el gravamen era de 20 sueldos por centenar. La expansión agraria de finales del siglo XIV en las comarcas montañosas del norte alicantino hizo que ésta se hiciera en detrimento de la ganadería, observándose una caída de esta renta en el conjunto de las exacciones señoriales.

En Ondara sólo encontramos tres propietarios de rebaños, que sumaban 280 ovejas: Mahomat Ell, alias Morit, que tenía 150 animales; Coot Dulegui

15. El Diccionario de la Lengua Española define la voz melcocha: "Miel que, estando muy concentrada y caliente, se echa en agua fría, y sobándola después, queda muy correosa.//2. Cualquier pasta comestible compuesta principalmente de esta miel elaborada". 
otras 80 cabezas, y Cilim Duueyech 50 ovejas, abonando un impuesto anual de 5 dineros por cabeza. En total el duque percibió 116 sueldos y 8 dineros.

- El derecho del barbero (dret del barber), cuyo obrador fue arrendado ese año por 9 sueldos. En otras localidades del duque la suma percibida por este derecho variaba, y en 1379 en los valles de Gallinera y Ebo era de 21 sueldos, mientras que en el de Castell era de 8 sueldos o de 10 en el de Guadalest, cifras muy parecidas a las de Ondara, pero que quedan muy lejos de las altas cantidades recaudadas en otras aljamas, como la de Benaguasil, arrendado anualmente a principios del Cuatrocientos por 300 sueldos, o en la de Paterna por 200, ambas pertenecientes al Antiguo Patrimonio de María de Luna ${ }^{16}$.

- En las bodas se abonaba el llamado dret de cuçea, que era el tercio del salario percibido por los juglares por su trabajo realizado en las nupcias que tenían lugar en Ondara ese año y consistía en el pago por el interesado de la suma de 7 sueldos y 6 dineros. Ese año se casaron Cayt Hayr; Cilim Rafe, Caat, barbero; su hermano Alí, también barbero, aunque no sabemos si "barber" designaba la profesión o era el apellido, aunque no era habitual entre los mudéjares los apellidos valencianos; Alí Albayre y Caat Benjama. En total 43 sueldos y 6 dineros. En otras localidades se conocía como dret de juglar y variaba la cantidad percibida en función de las bodas celebradas.

Los arrendamientos y citadas rentas proporcionaron al duque la suma de 1.379 sueldos y 8 dineros, equivalentes al 15,13\% de la renta señorial en ese año.

Formando parte de las prerrogativas del señor se incluía el derecho de justicia, una fuente de ingresos muy interesante que variaba según los años en función del número de delitos cometidos por los vasallos y su categoría. Para el historiador es también una fuente de primera importancia para aproximarnos al mundo de la delincuencia mudéjar, que en el caso de Ondara fue muy baja, limitándose a dos transgresiones de la ley por Mahomat Jayeni y Caat Alget, que dijeron palabras injuriosas a dos de sus convecinos. En cada uno de los dos casos los inculpados fueron condenados a la pena de 45 y 15 azotes, imaginamos que en función de la gravedad del insulto, y que el señor conmutó por el pago de 22 y 11 sueldos, respectivamente. Mucho más grave debió ser el delito cometido por Azmet Çamaya, que no se indica, pero que fue castigado con 20 florines, aunque el duque le perdonó cinco, mientras que el hijo de Caat Xoaya fue castigado con 11 sueldos por sacarle el cuchillo a un cristiano nuevo, sin que sepamos si era converso de judío o de musulmán, pero ejemplos de esta violencia contra los conversos no fueron raros tras los asaltos a las juderías valencianas en 1391. Hubo otra condena de 15 azotes, conmutada por

16. F.J. Cervantes Peris, La herencia de María de Luna. Una empresa feudal en el tardomedievo valenciano, Segorbe, 1998, p. 189. 
una multa de 11 sueldos, a Caat, barbero, pero no se indica la causa. En total, la señoría ingresó por ejercer la justicia la suma de 253 sueldos.

Este apartado, que la fuente califica como "esdeveniments e judgaments", incluye también otros variados asuntos, como fueron los 5 sueldos percibidos de la hija de Azmet Bachcora "que anà novia a Oliva e que cascú devia pagar cinch sous". Los noviazgos femeninos fuera de la aljama estaban penalizados con la suma de cinco sueldos, ya que el señor corría el riesgo de la marcha de una mujer, lo que suponía un futuro hogar menos, por lo que debía ser compensado con la citada cantidad.

Se incluyeron aquí los besantes abonados por Mahomat Mundo, moro del valle de Jalón, y de tres hijos de Coot Abencot, de Pedreguer, que se hicieron vasallos del duque, recaudando por este concepto 13 sueldos y 4 dineros. Por último hay que mencionar los 2 sueldos y 6 dineros que fue la tasa que pagó una "mora cabia", que ejerció la prostitución en Ondara en tres ocasiones, pagando como tasa 10 dineros en cada ocasión, de forma que quedaran satisfechas las necesidades sexuales de algunos varones de la aljama.

Los ingresos por este concepto fueron de 273 sueldos y 10 dineros, o sea el 2,99\% del total de la renta.

El último apartado de ingresos en este año estuvo integrado por el laudemio (los lü̈smes), que era el derecho del señor a cobrar un $10 \%$ del precio de las ventas que se hacían. La cantidad, como es natural, no era fija y variaba en función de las ventas realizadas cada año. En este concreto de 1408, el alamín de Ondara recaudó por dicho concepto la suma de 269 sueldos, que representan el 2,95\% de las rentas. Este año se realizaron 14 operaciones de ventas de tierras en la localidad, de las cuales 10 fueron realizadas por mudéjares, y las cuatro restantes por cristianos, de ellas una por "lo capellà", el clérigo encargado de la parroquia, que vendió unas casas a Joan Cardona. En 1416 aparece otro clérigo, Ramón Lombart, prévere, que vendió una viña a Joan Pelegrí, y otro trozo de viña a Joan Crespo, notario de Valencia, aunque no sabemos si se trata del mismo personaje. Ondara, hay que recordarlo, dependía en lo eclesiástico de Denia y no tuvo parroquia propia hasta el siglo XVI, en 1544, en que se erigió como parroquia independiente, con los anejos de Benidoleig y Pamís ${ }^{17}$. Destaquemos también la compra de tierras en Ondara, a cien kilómetros de Valencia, por un notario de esta ciudad, como un testimonio de la inversión en tierras por parte de la burguesía valenciana.

El laudemio es una fuente interesante para conocer las transacciones efectuadas con la propiedad, y gracias a estos datos que el cabreve nos suministra sabemos que las ventas fueron de casas y tierras. Por lo que respecta a las viviendas los precios eran variables, como es lógico, en función del inmueble: 12 libras

17. J. SANChIS Sivera, Nomenclátor geográfico-eclesiástico de los pueblos de la diócesis de Valencia, Valencia, 1923, p. 321. 
y 10 sueldos; 80 sueldos por otras casas; o el horno, vendido por 100 sueldos por Na Corneta a Ramón Salvador; un patio o corral por 40 sueldos; otras casas por 24 libras, etc. En lo referente a las tierras encontramos también situaciones variadas: un higueral fue vendido por 66 sueldos, mientras que un higueralito (" $f i$ gueralet") lo fue por la ínfima suma de 7 sueldos y medio; un trozo de viña por 8 libras, un trozo de tierra por 70 sueldos, o un trozo de majuelo por 88 sueldos; o tierra en la huerta por 17 libras y 2 sueldos, es decir un precio superior al de una vivienda, aunque la comparación no sea válida, ya que no sabemos las cualidades de una y otra ni el tamaño del trozo de tierra, pero en cualquier caso siempre es superior al del secano, viñedo o higueral. La venta más barata fue la de una viña yerma, hecha por Abrafim Corruma a Jaime Escrivà por 20 dineros, quien posiblemente la adquiriera para su posterior puesta en cultivo.

Todas las transacciones lo fueron entre individuos de la misma comunidad, salvo la venta de la citada viña yerma y dos trozos de tierra vendidos por Abdallá Çale a Joan Gençor y Mahomat Jayeni a Joan Cardona, y un trozo de majuelo de Alí Cuçén vendido a Francesc Palau.

Otra fuente de ingresos para el señor, procedente de la tierra, era l'arrendament dels figuerals, el arriendo de los higuerales, un cultivo tradicional en las comunidades mudéjares, que el duque de Gandía arrendaba cada tres años, del que conservamos los datos para el año 1416, en que hubo veinticinco mudéjares con campos de higueras, por los que abonaban cantidades que oscilaban entre los 2 y los 22 sueldos, dependiendo de la extensión del terreno. El señor percibió por dicho concepto la cantidad de 275 sueldos, pero al tratarse de una noticia suelta no podemos establecer su importancia dentro del conjunto de la renta de ese año.

\section{LA RENTA DE LOS CRISTIANOS}

La población cristiana de Ondara, además de la cantidad que les correspondiera abonar al señor en los 4.000 sueldos correspondientes a la partición de frutos, debía abonar por Navidad un censo de 4 sueldos por sus casas, que tenían acensadas del duque. Obsérvese que es la misma cantidad que abonaban los mudéjares por el besante, por lo que en este sentido existe una igualdad fiscal en cuanto a las cargas sobre la vivienda. Son en total 27 casas las que abonaban el censo, que en algún caso en lugar de los 4 sueldos habituales podía ser de cinco, nueve o quince sueldos, sin que sepamos el porqué, aunque respondería a las condiciones particulares estipuladas entre el señor y el censatario; o de once si incluía un trozo de tierra, o de 15 sueldos para unas casas y obrador. Variedad de situaciones, como puede verse, que, junto con los 550 sueldos por los que Joan Sanchiz tenía arrendada a perpetuidad la taberna y el hostal, proporcionaron a la señoría una renta de 713 sueldos y 6 dineros, el 7,82\% del monto global de los ingresos señoriales. 
También los cristianos estaban obligados a entregar al señor por Navidad diversas cantidades procedentes de las tierras, viñas y otras posesiones que tenían acensadas desde antiguo. Entre estas últimas, además de algún huerto, se incluía un molino que tenía Arnau Gavilà, menor, el cual, junto con casas y tierra abonaba un censo de 38 sueldos y 9 dineros, otro molino por 60 sueldos abonados por Pere López y unos molinos y tierra en manos de Berenguer Ortopeda por 40 sueldos y 8 dineros, mientras que el horno del lugar lo tenía Ramón Salvador por 25 sueldos, sin que faltara algún obrador de un zapatero. Pero en el conjunto predominaban los viñedos, y por todos ellos el señor ingresó 453 sueldos y 6 dineros, el 4,97 de la renta señorial. Es un porcentaje interesante, que no está lejos del que abonaban por el mismo concepto los mudéjares, sobre todo si tenemos en cuenta que el número de cristianos era inferior al de los musulmanes del lugar, lo que se explica, en buena medida, por el peso de los censos abonados por los tres molinos mencionados.

\section{LOS LAUDEMIOS DEL AÑO 1416}

Incluido en el cuaderno de las rentas de 1416 se incluye un cuadernillo sobre el laudemio de las posesiones vendidas en Ondara ese año, cobradas por el ya mencionado alamín, Abdallá Zale, del que tenía que rendir cuentas al señor. Ese año se realizaron un total de cincuenta transacciones de propiedades, por las que el señor ingresó una renta de 977 sueldos y 6 dineros, más del triple del año 1408.

Las operaciones de venta se realizaron, como en 1408, básicamente sobre propiedades agrarias: tierra de secano, algo de regadío y, sobre todo, viñas, a las que se añadieron algunas casas, variando los precios en función de la calidad y extensión del producto vendido.

La mayoría de los compradores y vendedores eran mudéjares de Ondara, aunque no faltaron algunos de lugares y alquerías del término o de la comarca, como Pinela, Benimazmut, Pamíes, Albardanera, Pedreguer, El Verger, Vall de Seta, Benissa y Denia, como puede verse en la prosopografía final. También hay que citar algunos cristianos, como Pere Martí, menor, que vendió un bancal de tierra a Hiayhe Cerbaní, o Joan Pelegrí otro trozo de tierra a Azmet Ceddi, por citar un par de ejemplos.

\section{UNA ECONOMÍA DE BASE AGRARIA}

Los datos aislados del año 1408 muestran que en estas fechas el cereal, la vid y los higos configuran la tipología de cultivos de los que el señor extraía el grueso de la renta feudal.

No hay duda de que a principios del siglo XV había mudéjares en Ondara que todavía conservaban la plena propiedad de sus tierras, tal como se 
desprende de la autorización concedida en 1403 por el duque don Alfonso a 27 musulmanes de Ondara para que pudieran vender sus tierras a Jaime Tamarit, por 2.800 sueldos, que luego podrían volver a cultivar en enfiteusis, quedando exentos del pago del laudemio y la fadiga debidos al señor, con el fin de poder pagar la deuda contraída con Mateu Dimita ${ }^{18}$.

El territorio se dividía para su aprovechamiento agrario en una huerta (l'horta), la tierra de secano, destinada básicamente a cereal, calificada en las fuentes como terra o terra de secà, el viñedo e higuerales, con predominio absoluto del secano sobre el regadío. La marjal estaba ocupada en parte por viñedo. Entre todos los cultivos destaca el de la viña, que a fines de la Edad Media en muchas comunidades mudéjares, como estas de la Marina o las del Valle de Elda, tenía un contenido fuertemente especulativo, de altos rendimientos, ya que su producto, transformado en forma de pasa, se incardinaba en el gran comercio internacional. Los puertos de Denia, y en menor medida Jávea, eran escala de las embarcaciones italianas, que cargaban la pasa con destino a Flandes, donde eran objeto de una fuerte demanda, siendo Valencia la ciudad desde donde se centralizaban estas operaciones mercantiles, en las que junto a las aljamas locales participaban mercaderes valencianos e italianos.

Por lo que hace a los cultivos arborícolas, ocupaban un lugar secundario en la producción local, combinándose con las posesiones de viñas y tierras, destinados al consumo doméstico, ignorando, por ejemplo, la importancia que pudiera tener el olivo, que nunca se menciona de forma explícita. En cambio, sí que tenían un importante peso en la economía familiar del mudéjar los higuerales, cultivo tradicional, de gran arraigo, que se mantuvo tras la conquista cristiana. Baste recordar la exención fiscal concedida a los habitantes de Calpe por Pedro III en 1280, favoreciendo la exportación de higos por dicho puerto, siempre que no fuera a países prohibidos ${ }^{19}$. Los higos los arrendaba el señor cada tres años, percibiendo su renta en la fiesta de San Miguel, finalizada la cosecha, y en el año 1416 fueron veinticinco los mudéjares con parcelas con higos.

Del almendro, cultivo que debía ser importante en la zona, pero del que se nos escapa su importancia real, sólo hay una noticia de 1410, en que Cayt Ciplana, moro de Ondara, se comprometió a entregar, bajo pena del cuarto, a Alí Allagrat, factor de Cilim Albatén, alfaquí de Beniopa, una carga de almendrón, a pagar en Ondara durante el mes de septiembre, que le vendió al precio de 60 sueldos la carga ${ }^{20}$.

18. A.R.V. Maestre racional, 9568, fol. 51 v-52 r. J. Hinojosa MonTALVo, op. cit., p. 115.

19. A.C.A. C, reg. 59, fol. 57 r; V. Llopis Bertomeu, Calpe, Alicante, 1975, p. 258.

20. "Cayt Ciplana, moro del loch d'Ondara, de sa plana vollentat se obliga en donar he librar sots pena del quart a Alli Allagrat, seray d'Ondara, fachtor he procurador de Cillim Albaten, alfaquí de Beniopa, una càrega d'amelló, bo e rebedor, librar hi pagar en lo loch d'Ondara per tot lo mes de setembre, la qual li a venut a raó de $L X$ sous la quàrega. E confesà aver agut hi rebut lo preu de la dita miga càrega, que és XXXX sous. E per acò atendre hi cumplir si hi sos béns". 
Aunque lo habitual era que las tierras de los mudéjares limitaran con campos de otros correligionarios, no era raro que lo hicieran con posesiones de cristianos de la localidad, sin que hubiera una separación total de la propiedad de ambas comunidades. Algunos huertos, dado el valor de este tipo de propiedad, estaban cerrados, pues se castigaba con multas a los que entraran en aquellos que tuvieran dos tapias de altura. Se considera que el tapial más utilizado era el de $84 \mathrm{~cm}$, que tenía como referencia el codo ma'muni.

De las técnicas agrarias utilizadas por los mudéjares encontramos la mención de la labranza, que se hacía con animales, además de las labores de la poda y la cava, y sabemos que se practicaba la técnica del injerto, ya que los que destruyeran árboles injertados serían castigados con una multa de tres sueldos. Respecto al regadío el cabreve menciona un pozo y una cenia, ambos juntos, en manos de Cayt Azeyn, que tenía a censo junto con tierras de secano y viñas, siendo un sistema habitual de extracción de agua en esta comarca. El riego se efectuaba también mediante la utilización de acequias, de la que conocemos el nombre de la "céquia del moli appel·lat d'En Coll", así como la "céquia comuna", de utilización conjunta por todos los vecinos del lugar.

Quedan planteados numerosos interrogantes, que nos impiden conocer el grado de desarrollo de la agricultura en la localidad, como son el tamaño de las parcelas, la forma de rotación de los cultivos, la extensión del barbecho, la distribución de las cosechas, la utilización del abono, instrumental utilizado por cada familia, la comercialización de estos productos agrarios, o los rendimientos alcanzados.

La ganadería no puede considerarse como una actividad específica entre los mudéjares de Ondara, pues sólo tres vecinos se dedicaban a ello, a tenor del derecho del herbaje, con tres rebaños de 150, 80 y 50 ovejas, que totalizaban 280 cabezas.

La mayoría de los habitantes en Ondara a fines de la Edad Media eran agricultores de profesión, ya fueran musulmanes o cristianos. Más difícil es conocer otras actividades de los sectores secundario y terciario, aunque en ocasiones una apostilla junto al nombre del interesado, indicando su profesión, nos permite conocer otras profesiones de carácter más urbano y habituales en la mayoría de las comunidades mudéjares, como era caso de Caat Morraxo, que ejercía como juglar de la localidad. Con su actividad en los acontecimientos públicos y privados de la aljama, en particular las bodas, contribuía a alegrar la vida de sus convecinos, y no debemos olvidar que estos juglares moros valencianos eran muy reputados por todas partes y sus servicios eran requeridos por particulares, incluidos los propios monarcas, que a menudo los llamaban a la corte, o las instituciones municipales, para alegrar las fiestas con su música, juegos y espectáculo. Tampoco faltaron el barbero o el carnicero, arrendándose el obrador destinado a barbería.

Pero en Ondara se atisba también la existencia de una actividad artesana muy interesante, difícil de rastrear al no estar gravada con exacciones directas, y que se destinaba a satisfacer la demanda de una clientela local e incluso comarcal, 
como era, por ejemplo la cantarería, en la que se fabricarían piezas de uso doméstico, y el propio nombre sugiere que los cántaros serían la pieza que mayoritariamente se fabricara. En 1408 Fumeyt Alvalencí abonaba, junto con tierras -quizá de donde se aprovisionara de materia prima-, 40 sueldos de censo al señor.

Otra artesanía en la que despuntaron los mudéjares fue la fabricación de jabón, que en Ondara en 1408 llevaba a cabo un tal Alget, abonando 11 sueldos al señor como derecho, lo que indica el carácter modesto de la empresa. Otras profesiones habituales en las aljamas mudéjares, que nunca faltaban, eran la de herrero, en este caso Yaeix Yhaymet, alias Mequiquo, que tenía su obrador en la plaza, o la de carpintero, un tal Azmet, de los que desconocemos su grado de especialización, si se dedicaban a reparar o fabricar aperos de labranza o producían artículos más específicos.

No obstante, quizá el testimonio más interesante de esta actividad artesana sea la mención que se hace de la tintorería, que poseía Abrafim Çale, y junto con otras casas rentaba al señor 50 sueldos, lo cual testimonia una industria textil de carácter rural, modesta, pero capaz de llevar a cabo el proceso de fabricación de paños, incluido el complejo apartado del tinte. Completa la información de esta pañería la mención de un tal Abrafim Loppo, "pinter", es decir fabricante de peines para cardar la lana, que tenía un obrador en la plaza, y de otro personaje, un tal Hiayhe, dedicado a la misma tarea, lo que sugiere una especialización del trabajo, muy precisa, que indica un cierto volumen de consumo interno de este producto o una posible exportación a otros puntos, superando el marco local. Ignoramos su alcance y si esta pañería local era controlada por los propios mudéjares o lo era por los cristianos de la localidad o de la cercana Denia. He encontrado mención de hasta siete obradores, la mayoría de los cuales se hallaban enclavados en la plaza del lugar, su punto más céntrico, el corazón de la comunidad.

De las actividades de la comunidad cristiana ondareña, aparte del labrantío de las tierras, poco más podemos decir que unas alusiones a unas actividades secundarias y terciarias muy débiles, al menos a tenor de esta documentación: dos sastres, Pere Boïl y Joan Gençor; un zapatero, Jaime Roiz; el capellán, y una actividad transformadora de los productos agrarios en los varios molinos dispersos por el término. La transformación de los productos agrarios, básicamente el grano, se realizaba en los varios molinos dispersos por el término, ya citados, de los que sólo uno, el molí d'En Coll, aparece especificado por su nombre. En el sector servicios se citan el horno, la carnicería, la taberna y hostal, del que era hostalero Miquel Pérez, y cuatro obradores, indicio de una posible actividad artesana inferior a la de los mudéjares. Pero la falta de datos impide más precisiones.

En cualquier caso, y aun desconociendo la importancia real y el valor absoluto de estas actividades artesanas en la empresa señorial, no cabe duda que aportaban un complemento numerario a las economías campesinas, que les permitía hacer frente a las obligaciones fiscales señoriales y municipales, e incluso obtener unos excedentes para invertir en compras de otros bienes en el mercado local o en el de la propiedad, pero siempre moviéndonos en un marco local. 


\section{UNOS DATOS SOBRE URBANISMO Y TOPONIMIA}

Es imposible saber el aspecto que tenía Ondara a comienzos del siglo XV, ya que no hay ninguna descripción del lugar, y tan sólo algunas noticias aisladas entre las mencionadas rentas que nos permiten recuperar algo de la toponimia de la época. El caserío sería humilde, con casas de piedra, aunque ignoramos si estaba amurallado. La única noticia del viario se refiere a la plaça del dit loch, la única existente, en la que se localizaban algunos de los obradores, como, por ejemplo, la herrería.

En el entorno rural de Ondara hemos localizado menciones del río Girona, que en ocasiones se designa simplemente como "lo riu", y las acequias del molino d'En Coll y la acequia común. De las partidas rurales sólo se cita en dos ocasiones en 1418 la Marjal (Margall), que en parte, al menos, debía estar transformada en tierras de cultivo, pues la documentación alude a la venta de campos de viñas y de un majuelo en la misma, y aparece como un testimonio de la recuperación agraria de la comarca, superadas las dificultades bélicas de la guerra de los dos Pedros, aunque no podemos precisar el momento de su desecación y conversión en tierra de labor y la extensión que ésta alcanzó.

También en 1418 aparece mencionado un trozo de tierra "appel-lat l'Alffacara", que lindaba con el camino de Denia y con el de Jávea. Estas dos vías de comunicación, junto con el camino de Beniarbeig, son las únicas que la documentación menciona en el citado año.

\section{BALANCE FISCAL}

Al final del cabreve se hace constar que la renta extraída de la localidad en este año de 1408 ascendió a la suma de 9.111 sueldos, 7 dineros y mealla, siendo el alamín del lugar, Cayt Barberí, el encargado de su recaudación, mientras que el balance final fue presentado al señor por Ramón Vidal, notario y baile de Ondara, después de reconocer "una e moltes vegades" los libros de cuentas, y de que el alamín jurara "per Déu e per la quibla de Mahomat" que dicha cuenta era verdadera. Recordemos que la misión fundamental de los alamines era la defensa y conservación de los derechos y bienes de sus señores y de su aljama, encargándose por ello de la recaudación de las contribuciones, pago de gastos, etc., siendo presidentes de las aljamas que no contaban con alcadí propio ${ }^{21}$. El baile cobró 5 sueldos y medio por escribir el cuaderno de las citadas rentas. Esta renta se desglosa en una serie de apartados, como podemos ver en el siguiente cuadro:

21. M.V. Febrer Romaguera, «Organización y administración de las aljamas mudéjares valencianas», Crónica de la XVIII Asamblea de Cronistas Oficiales del Reino de Valencia, Valencia, 1990, pp. 184-192; id., «La administración económica e las aljamas mudéjares valencianas a través del oficio del alamín», Actas del IV Simposio Internacional de Mudejarismo, Teruel, 1993, pp. 261-280. 


\begin{tabular}{lcc}
\hline IMPOSICIONES & CANTIDAD (SUELDOS) & PORCENTAJE (\%) \\
\hline Por casas de moros & 1.328 & 14,57 \\
Por casas de cristianos & 713 & 7,82 \\
Censales antiguos de los cristianos & 453 & 4,97 \\
Censales antiguos de los moros & 697 & 7,65 \\
Partición frutos moros y cristianos & 4.000 & 43,90 \\
Arrendamientos & 1.379 & 15,13 \\
Sucesos y justicia & 273 & 2,99 \\
Laudemios & 269 & 2,95 \\
\hline
\end{tabular}

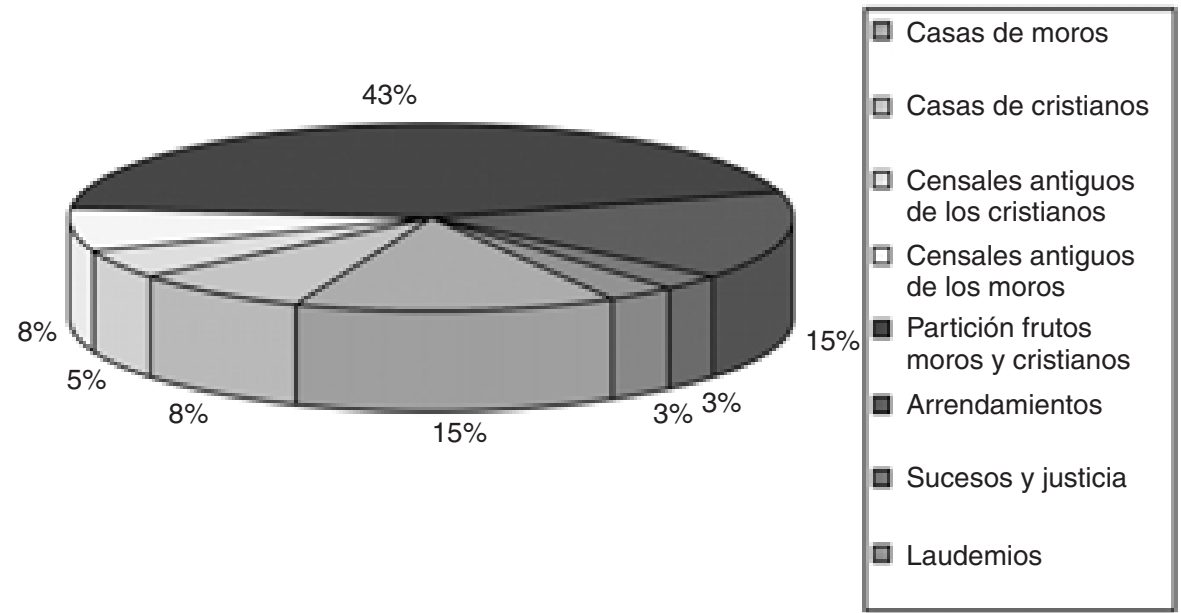

Porcentajes de las rentas de Ondara en 1408.

Como se puede apreciar era la partición de frutos de los mudéjares y los cristianos, con sus 4.000 sueldos, la que proporcionaba los mayores ingresos en las arcas señoriales, es decir, el gravamen sobre la actividad económica de la localidad, seguida por los arrendamientos y el besante, en proporciones similares, correspondiendo porcentajes menores al resto de los conceptos analizados, apareciendo en último lugar, prácticamente con un $3 \%$ cada uno, los derechos de justicia y los laudemios, ingresos cuyo porcentaje variaba anualmente en función de los delitos o transacciones de la propiedad llevados a cabo.

Por lo que hace a la presión fiscal, no hay duda de que el señor obtenía sus mayores ingresos de los vasallos mudéjares, pues aunque el censo de casas de ambas comunidades pagan la misma suma de 4 sueldos, existen otras muchas car- 
gas y monopolios cuya exacción fiscal se aplicaba en exclusiva a los mudéjares, en virtud de los pactos de capitulación firmados por la aljama con el señor, en tanto que los cristianos además de los laudemios sólo estaban gravados aquellos que poseían tierras, viñedos y otras posesiones acensadas. Por tanto, el grueso de los ingresos señoriales procede de la tierra, frente a los cuales, los procedentes de los monopolios, derechos de justicia, etc., ocupan un papel secundario. Desgraciadamente, sólo tenemos los ingresos, faltando los gastos habidos ese año en la señoría, por lo que no sabemos cuál fue el balance final de la renta feudal.

Al final del cuaderno hay una noticia sobre el total de las rentas del señor en Ondara, que ascendieron ese año a 9.111 sueldos, lo que muestra una tendencia alcista de las mismas y la buena marcha económica del lugar a comienzos del Cuatrocientos. Lo realmente interesante hubiera sido poder cotejar esta suma con los ingresos en otras localidades del señorío en la misma comarca, tarea, por el momento, imposible de llevar a cabo.

\section{LAS ORDENANZAS MUNICIPALES DE 1410}

El cabreve recoge al final del mismo en un par de hojas una serie de acuerdos adoptados por los prohombres y jurados cristianos y la aljama de Ondara en el año 1410, y que por su interés para la historia de la localidad vale la pena ennumerar. Son los siguientes:

- En primer lugar, si alguna persona entraba en el coto de otro y no se llevaba nada, pagaría de multa 10 sueldos si era de día y 60 si era de noche.

- Si alguien entraba en un huerto cerrado que tuviera dos tapias de alto, pagaría una multa de 60 sueldos de día y el doble de noche si no se llevaba nada o no tenía una excusa justificada para haber entrado.

- Si algunos animales, grandes o pequeños, entraban en lugares con plantaciones nuevas o en otro lugar cualquiera, como ganados, barbechos, humedales, pagarían 4 dineros de multa por cada cabeza de bestia mayor y la mitad si era menor. Si la transgresión se producía de noche pagaba el doble.

- El que cortara a ojo de cualquier árbol se le multaría con un sueldo.

- Si cortaba un brote de un árbol mayor, la multa era de 1 dinero.

- Si cortaba un injerto y éste pudiera perderse, se le multaba con 3 sueldos.

- Se prohibía meter ganado menor en las viñas o en majuelos, propios o extraños, en ninguna época del año, bajo la pena de 60 sueldos.

- Si entraban ocas en lugares donde se estuviera haciendo tala -cabe entender como siega-, pagaría de multa dos dineros, y si eran gallinas 1 dinero, o cuatro dineros en caso de ser un gallo.

- Si alguno iba a podar o a cavar, se le autorizaba a meter sus animales de labranza mientras araba o podaba. 
- Que ningún animal vaya suelto sin guardián, bajo multa de dos dineros de día, o seis de noche.

- El animal que no llevara bozal debería caminar detrás de su dueño, bajo la pena de 4 dineros.

Las multas, como era habitual, se repartían en tres partidas: un tercio para el señor, otro para el dueño de la posesión, y la tercera para el acusador.

Como puede apreciarse se trata de unas normas muy sencillas, como las que encontramos en cualquier otra población del reino, que nos muestran una comunidad de agricultores, en la que la preocupación esencial era la protección de la propiedad privada de cualquier intrusión extraña, sea de personas o, fundamentalmente, de los animales, que tantos daños causaban cuando entraban en los campos de labor, síntoma de que el crecimiento agrario no dejaba mucho margen para que el ganado paciera por el término, y aunque ya vimos que éste no era muy numeroso, estaban los animales domésticos, que vagaban sueltos por los campos, siendo más difíciles de controlar. Particular atención, como era habitual, merecían las viñas y los árboles, en particular los injertados.

\section{PROSOPOGRAFÍA}

Aparecen aquí recogidos los nombres de todos los musulmanes y cristianos de Ondara en los años 1404, a partir del impuesto del morabatín; los citados en 1408 en el cabreve analizado, y los indicados en los laudemios de 1416, así como los poseedores de higuerales.

ABACHTORA, Azmet, besante de 1408.

ABBEZ, Cayt, en 1416 se cita un trozo de tierra suyo en un deslinde de propiedad en la venta de un trozo de tierra por Pere Martí.

ABDALLÁ, carnicero, besante de 1408.

ABDULEGUI, Çoot, en 1416 poseía un higueral.

ABDUQUEYECH, Çilim, en 1416 poseía un higueral.

ABENAFÉN ALI MAZERANO, Gemé, alias Manzano; arrendador de la carnicería en 1408.

ABENAFÉN, Gemé, besante de 1408.

ABENAMER, Hiayhe, en 1416 se cita un trozo de tierra suyo en un deslinde de propiedad en la venta hecha de tierra por Hiayhe Alcocer a Azmet Manorquí.

ABENAYEN, Ayén, besante de 1408, censal.

ABENAYET, Alí, o Abenhayet. Censal en 1408. En 1416 se cita como poseedor de un trozo de tierra en un deslinde de propiedad en la venta que Alí Alagraz hizo de un trozo de tierra a Mahomet Abeyale.

ABENCABER, Azmet, arrendador del derecho de la "melcucha" en 1408 por 27 sueldos, 6 dineros. 
ABENCOT, Coot. De Pedreguer, cuyos tres hijos se hicieron vasallos del duque, por lo que pagan como besante 10 sueldos (1408).

ABENÇALÉ, Çalé, morabatín de 1404, citándose también sus hijos herederos de la otra mujer; censal en 1408. En 1416 compró un trozo de viña a Benachen, alias Barberí, por 4 libras. Lindaba con otra viña suya. Poseía un trozo de tierra que lindaba con otro de Abdallá Zale, alamín.

ABENJALCHAFAR, Caat, en 1416 aparece citado como testigo en la venta de un trozo de tierra de Ramón Lombart, presbítero.

ABENJAMA, Caat, morabatín de 1404; censal en 1408.

ABENTHAER, Alí, vendió unas casas en 1408.

ABENTHAEZ, Fomdell, besante de 1408.

ABEYALE, Mahomet, en 1416 compró un trozo de tierra a Alí Alagraz por dos libras.

ABENYAREN, Ayén, morabatín de 1404.

ABEYAYA, Azmet, besante de 1404, censal.

ABDULEGUI, Coot, besante de 1408.

ABOLAIX, Ayet, morabatín de 1404; besante de 1408, censal. En 1416 se le cita en una venta de unas casas de Caat Gananeri, de la Vall de Seta.

ABOLAIX, Caat, besante de 1408 .

ABOLAN, Ayet, de Ondara. Compró en 1416 un trozo de tierra a Coot Barberí por 11 sueldos.

ABZEQUENDEL, Mahomat, en el morabatín de 1404 se cita a su mujer; en el besante de 1408 aparece su viuda, aunque en otro apartado en lugar de viuda se la califica como "muller de". Citado en los censales de ese año.

AÇET, Al, morabatín de 1404.

AÇET, Azmet, besante de 1408, censal.

ACET, Mahomat, besante de 1408 .

AÇET LORP, Caat, besante de 1408, censal. En 1416 vendió la mitad de su casa a Coot Xadit por 3 libras.

AJUBA, Abrahim, se le cita una posesión de tierra suya en 1416 en el deslinde de la venta de un molino en la partida del marjal, hecha por Mahomet Albaçar.

AJUBEYT, Caat, de Albardanera. En 1416 compró una casa a Hiayhe Bexir, moro de Ondara.

AL MAXITA, Axuix, de Orba. Arrendador en 1408 del derecho de la almaxita de Ondara por 24 sueldos.

ALACIR, Cayt, besante de 1408.

ALAGRÁS, Alí, o Alagraz. Besante de 1408. En 1416 aparece como testigo en la venta de un trozo de tierra por Pere Martí a Hiayhe, el pintero. Vendió a Mahomet Abeyale un trozo de tierra por 2 libras. Vendió a Joan Pelegrí un trozo de tierra en la huerta por 3 libras y 11 sueldos. 
ALAZLA, Cayt, alias Martorell, de Pedreguer. En 1416 se le documenta en la venta de 41 sueldos censales a Francesc Palau, de Denia, por 26 libras.

ALBAÇ, Alí, en 1416 poseía un higueral.

ALBAÇAR, Mahomet, de Beniarbeig, que en 1416 vendió a Açayhec Coruli, de Beniarbeig un molino en el marjal por 1 libra, 13 sueldos.

ALBACHTORA, Azmet, también Bachora. Besante de 1408. En 1416 poseía un higueral.

ALBAYRE, Alí, o Albayrí; morabatín de 1404; besante de 1408. Este año abonó 7 sueldos y 6 dineros al duque de Gandía como impuesto por sus bodas. Citado en 1416 en una delimitación de propiedad, poseía tierras lindando con las de Cayt Caydón.

ALBAYRE, Ayet, besante de 1408.

ALBAYRÍ, vid. Albayre.

ALBOCAYRINÍ, Alí, morabatín de 1404, citándose en otra unidad familiar su hijo heredero de la otra mujer; besante de 1408. Se citan también su mujer y sus hijos acensados.

ALBOCAYRINÍ, Abdallá, su mujer y su hija; besante de 1408.

ALCÁCER, Abrafim, morabatín de 1404; besante de 1408, censal. Citado como testigo de una venta de tierra en 1416. Poseía tierra que lindaba con la de su pariente Hiayhe, así como una viña que lindaba con otra de Miquel Pérez, hostalero. Poseía un higueral en 1416.

ALCÁCER, Coayat, o Cuayeyt. Morabatín de 1404; besante de 1408, censal. En 1416 poseía un higueral.

ALCÁCER, Coot, morabatín de 1404; censal en 1408. Citado en 1416 como testigo en una venta de tierra.

ALCÁCER, Mahomat, morabatín de 1404. En 1408 fue condenado por sospechoso de robo, junto con Abdallá Nadir y el hijo de Baqua, condenados a 33 sueldos.

ALCÁCER, Yaye, morabatín de 1404; besante de 1408, censal. Compró de Yaye Redovà un trozo de tierra y un higueral por 66 libras. En 1416 vendió un trozo de tierra plantado de viña a Mahomat Lopello, por 4 libras y 8 sueldos. Otro trozo de viña a Miquel Pérez, de Ondara, por 4 libras. Tenía tierra que lindaba con otra de Azmet Aloret y Cacir, alfaquí. Vendió a Alí Albayrí, de Pedreguer, un trozo de tierra.

ALCAJAR, besante de 1408.

ALCAJAR, Caat, hermano de Facén, al que en 1408 compró unas casas que había heredado de su padre. Citado en el besante de 1408; censal.

ALCAJAR, Facén, en 1408 vendió su parte de unas casas que heredó de su padre a Caat, su hermano.

ALCASPÍ, Halléis, en 1416 compró a Caat Caydón dos trozos de tierra por 9 libras. 
ALCHACAN, Azmet, en 1416 vendió a Caat Raffe un trozo de tierra de secano por 20 libras.

ALCHAGAR, Alí, en 1416 compró un trozo de viña a Cayt Zimar.

ALFAFAR, Caat, besante de 1408.

ALFAMBRA, Azmet, censal en 1408.

ALFULEY, Mahomat, besante de 1408.

ALGAGUÍ, Caat, morabatín de 1404; besante de 1408, censal.

ALGAGÜÍ, Mahomat, morabatín de 1404; besante de 1408, censal.

ALGAGÜÍ, Ridwán, censal en 1408.

ALGET, Caat, morabatín de 1404. Abonaba al señor 11 sueldos por el "dret de çaboneria"; besante de 1408. Este año vivía su madre, identificada como otra unidad familiar diferente. Fue condenado a 15 azotes por decir palabras injuriosas en 1408, y conmutada la pena por 11 sueldos.

ALÍ, barbero, morabatín de 1404 .

ALLIR, Alí, morabatín de 1404; censal en 1408.

ALMALLEM, Caat, se cita su casa en un documento de 1416 delimitando la venta de una casa de Azmet Cumayia.

ALMANOR, Ayén. Posiblemente sería el personaje citado como Almanorquí.

ALMANORQUí, Alí, en 1416 compró a Hamer Almanorquí una viña por 1 libras y 18 sueldos. Vendió otra viña por 2 libras a Azmet Bincha.

ALMANORQUÍ, Ayén, se le cita en una venta de tierras en 1416 y poseía una propiedad en la huerta de Ondara. En 1416 se le cita en un deslinde de propiedad, indicando que tenía "tierra".

ALMANORQUÍ, Azmet, en 1416 compró a Hiayhe Alcocer un trozo de tierra por 1 libra y 10 sueldos.

ALMANORQUÍ, Hamer, de Pamíes. En 1416 vendió una viña por 1 libra y 18 sueldos a Alí Almanorquí.

ALMAXITA, Ayuix, besante de 1408.

ALMORIT, Caat, besante de 1408, censal. También con la grafía Almurit. Citado como testigo en 1416 en la venta de una casa de Azmet Cumayia. Poseía un higueral.

ALMORIT, Mahomet, citado en 1416 en la venta de 5 sueldos censales a Francesca Dalmau, notario de Gandía por 6 libras.

ALMURIT, vid Almorit.

ALOCAYLA, Cilim, en 1416 poseía un higueral.

ALOÇAYLA, Mahomat, morabatín de 1404; tenía un hijo pequeño, que también figura en el morabatín; besante de 1408.

ALORET, Azmet. En 1416 vendió a Cacir, alfaquí, un trozo de viña por 2 libras y 5 sueldos, y a Rodová, alfaquí, una viña por 2 libras y 5 sueldos. 
ALVALENCÍ, Fumeyt, besante de 1408. También como Valentí. Compró en 1408 unas casas a Alí Abenthaer.

AMDI, Azmet, de El Verger. En 1416 vendió un trozo de tierra a Cayt Mondoll, de Pinela, por 10 libras.

AMER, Azmet, o Hamer, censal en 1408. En 1416 vendió un "carreró", a Redovà, alfaquí, por 6 sueldos.

AMER, Geme, citado como testigo en la venta de un trozo de tierra en 1416. Ese año compró un trozo de tierra a Cayt Caydón, de Ondara, por 18 libras.

ANANYAR, Yaye, morabatín de 1404.

ARET LORP, Caat (1408).

ARRAIC, Ubequer, morabatín de 1404; censal en 1408.

ASILA, Hiayhe, de Benimazmur. Citado como testigo en la venta de un molino en la partida del marjal.

AYMER, Mahomat, citado en 1416 en una venta de tierra a Galip Xuqueyhec, de Matosses, poseía un campo que lindaba con otro de Joan García, de Denia.

AXER, Abadallá, besante de 1408, censal.

AXER, Coot, citado en 1416 como dueño de una viña en un deslinde de propiedad en la venta de un molino en la partida del marjal.

AXUAYA, Caat, en 1416 poseía un higueral.

AXUAYA, Cilim, en 1416 poseía un higueral.

AYZONPARA, viuda, besante de 1408.

AZEYN, Cayt, morabatín de 1404; besante de 1408, censal.

AZMET, carpintero, morabatín de 1404; besante de 1408, censal.

AZQUER, Ubequer, besante de 1408.

BACHCORA, Azmet, o Bacora; morabatín de 1404; besante de 1408, censal.

BACHCORA, Azmet, su hija. Tenía novio en Oliva, besante de 1408.

BACHCORA, Caat, o Albachcora; morabatín de 1404. En 1416 se le cita en un deslinde de propiedad, indicando que tenía "tierra". Ese año compró unas casas a Caat Caydón por 14 libras y 15 sueldos, y otras casas a Caat Gananeri, de la Vall de Seta por la misma suma. Tenía tierra en la huerta de Ondara y en una ocasión se le cita como "moro d'Ondara". Poseía un higueral.

BACHCORA, Mahomat, citado en 1416 como testigo en la venta de una casa de Mahomet "lo pellero".

BACORA, vid. Bachcora.

BAÇEM, el hijo de, besante de 1408.

BAQUA, Alí, citado como dueño de unas casas en un deslinde de propiedad hecho en la venta en 1416 de unas casas de Azmet Parell. 
BAQUA, Azmet, morabatín de 1404; besante de 1408, censal. Tenía un hijo, que en 1408 fue condenado por sospechoso de robo, junto con Mahomat Alcácer y el hijo de Abdallá Nadir, siendo condenados a 33 sueldos de multa.

BARBER, Alí, hermano de Caat, en1408 pagó al duque de Gandía 7 sueldos y 6 dineros como derecho por sus bodas.

BARBER, Caat, en 1408 pagó al duque de Gandía 7 sueldos y 6 dineros como derecho por sus bodas. Fue condenado ese año a 15 azotes por el baile, siendo redimido de dicha pena por 11 sueldos.

BARBERÍ, Cayt, era alamín del lugar en 1408; pagó el besante ese año.

BAZQUERI, Caat, besante de 1408 .

BAZQUERÍ, Cayt, besante de1408. En 1416 se cita la tierra de Bazchari en un deslinde de propiedad. No sabemos si sería este personaje, con grafía deformada por el escribano.

BAZQRIN, Coaytal, morabatín de 1404.

BAYRINÍ, alias Cacha, Azmet, besante de 1408.

BENACHEN, Coot, alias Barberí, en 1416 vendió un trozo de viña a Zale Abenzale por 4 libras, y otro de tierra a Ayet Abolan, de Ondara, por 11 sueldos.

BENEN, Cayt, o Benne. Citado en 1416 como testigo en la venta de unas casas de Caat Gananeri, de la Vall de Seta.

BENEXEBER, Melich, citado como testigo en 1416 en la venta de un molino en la partida del marjal.

BENJAMÁ, Caat, besante de 1408. Se casó ese año y abonó 7 sueldos y 6 dineros al duque de Gandía por dichas bodas.

BENXEBELL, Caat, en 1416 se cita una viña suya en un deslinde de propiedad, en la venta de un trozo de tierra de Ramón Pelegrí a Cayt Zintar.

BENZABER, Azmet, o Benzeber, Benzober. Citado en 1416 como testigo en la venta de una viña. Ese año compró a Joan García, de Denia, un trozo de tierra de riego, que lindaba con tierra de Bocayriní y con una acequia comunal, tierra de Ceddi y camino público, por 14 libras. También compró por 11 sueldos un huertecito al alfaquí Rodová. Poseía una casa que enfrentaba con la de Mahomat Lopello, luego vendida a Huayhe Maxato.

BENZUQUEYA, Mahomet, en 1416 vendió a Cilim Raffe un trozo de tierra de secano por 160 sueldos.

BEXIR, Hiayhe, en 1416 vendió una casa a Caat Ajubeyt, de Albardanera, por 3 libras y 10 sueldos.

BOCAIRINI, Caat, citado en 1416 como testigo de la venta de un trozo de tierra de Azmet Connayia.

BOCAIRINÍ, Mahomat, los hijos de, besante de 1408.

BOCHOROÓN, Hiayhe, de Pinela. En 1416 vendió una viña a Cayt Cedela, de Benissa. 
BOLAIX, Caat, morabatín de 1404, en el que también se cita a su mujer; besante de 1408.

CAAT, barbero, morabatín de 1404 .

CAAT, carpintero, morabatín de 1404; censal en 1408.

CACIM, Coot, morabatín de 1404; besante de 1408.

CACOL, Azmet, citado en 1416 como testigo en la venta de un trozo de tierra.

CACIM, Cot, en 1416 poseía un higueral.

CACIM, Maymó, morabatín de 1404; besante de 1408, censal en 1408.

CACIR, alfaquí, en 1416 compró un trozo de viña a Azmet Aloret por 2 libras y 5 sueldos.

CAJAR, Alí, yerno de Mahomat Alfuley, besante de 1408.

CALANCA, Cayt, morabatín de 1404, censal en 1408. En 1416 poseía un higueral.

CALIM, Coet, besante de 1408 .

CAMAYID, Azmet, citado en 1416 en una delimitación de propiedad en la venta de un trozo de tierra hecho por Azmet Alchatan. Poseía tierra en el secano.

CATAL, en 1416 poseía un higueral.

CATÁN, Azmet, morabatín de 1404; besante de 1408, censal.

CAYDÓN, Caat, o Caydó. En 1416 vendió a Caat Bacora unas casas por 14 libras y 15 sueldos. Vendió otros dos trozos de tierra a Halleis Alcaspí por 9 libras.

CAYDÓN, Mahomat, citado como dueño de unas casas en un deslinde de propiedad hecho en la venta en 1416 de unas casas de Azmet Parell.

CAYT, lo Curt, citado en 1416 como testigo en la venta de un trozo de tierra de secano por Azmet Alchatan.

CEDELA, Cayt. De Benisa, que en 1416 compró una viña a Hiayhe Bochorno, y una casa a Hiayeix Caydón, de Ondara, por 13 libras. Ese año aparece citado también como moro de Ondara, aunque no sé si se trata del mismo personaje. Vendió un trozo de tierra a Gemer Hamer por 18 libras.

CETDIN, Azmet, censal en 1408. Quizá sea el Azmet Ceddí que en 1416 compró un trozo de tierra a Ramón Pelegrí.

CERBANÍ, Hiayhe, en 1416 compró un bancal de tierra de riego a Pere Martí, menor.

CEYEN, Mahomet, citado en 1416 como testigo en una venta de tierras.

COMPARET, Mahomat, besante de 1408 .

COMPARETA. Ignoro si se trata del Mahomat Comparet citado en 1404. Aparece en el morabatín de 1404.

CONNAYIA, Azmet, en 1416 vendió a Miquel Pérez, hostalero de Ondara, un trozo de tierra por 40 libras. 
CORRUMA, Abrafim, en 1408 vendió una viña yerma a Jaume Escrivà, sayón, por 20 dineros.

CORULI, Açayhet, de Beniarbeig, en 1416 compró un molino en la partida del marjal de Ondara a Mahomet Albaçar.

CUMAYIA, Azmet, en 1416 vendió a Joan Ruiz de Corella, labrador en Gandía, una casa en Ondara.

CUZULI, Azmet, morabatín de 1404; besante de 1408.

ÇACAL, Azmet, besante de 1408, censal. Citado en 1416 como testigo en la venta de una casa de Mahomet "lo pellero".

ÇAYDÓN, Hiayeix, en 1416 vendió una casa a Cayt Cedela, de Benissa, por 13 libras.

ÇALE, besante de 1408.

ÇALE, Abdallá, o Zale; censal en 1408. Ese año vendió un trozo de tierra a Joan Gençor por 40 sueldos. En 1416 era el alamín del lugar. Se le documenta como dueño de un trozo de tierra, que lindaba con otro de Zale Abenzale.

ÇALE, Abrafim, besante de 1408, censal. Citado como testigo en 1416 en una venta de un trozo de tierra.

ÇALE, Çaat, besante de 1408.

ÇALE, Mahomat, morabatín de 1404; besante de 1408, censal.

ÇALE, Ubequer, de Pamíes. Citado como testigo en la venta de un trozo de tierra en 1416. y en un deslinde de propiedad hecho en la venta en 1416 de unas casas de Azmet Parell.

ÇAMAYÁ, Azmet, besante de 1408, censal. El baile de Ondara lo condenó a una multa de 20 florines, aunque el duque le perdonó cinco.

ÇAMAYA, Azmet, morabatín de 1404.

ÇATAL, morabatín de 1404. Un Azmet Çatal aparece como testigo en la venta de una viña de Mahomat Parrell en 1416.

ÇUÇÉN, Alí, morabatín de 1404; besante de 1408, censal. También Cucén. Ese año vendió un trozo de majuelo a Francesc Palau, de Denia, por 88 sueldos.

DULEGUI, Coot, morabatín de 1404; besante de 1408. Poseía un rebaño de 80 cabezas.

DUQUEYECH, Azmet, citado en 1416 como testigo en la venta de un trozo de tierra de Azmet Connayia.

DUQUEYECH, Cilim, morabatín de 1404; besante de 1408, censal. Poseía un rebaño de 50 cabezas.

DUQUEYECH, Galip, citado en 1416 como testigo en una venta de un trozo de tierra.

ELLI AL MORIT, Mahomat, besante de 1408. Poesía un rebaño de 150 ovejas. 
EXADIT, vid Xadit.

EXEM, besante de 1408, censal.

EXEM, Venic, de Pinela. Citado en 1416 como testigo en una venta de tierras.

FACAB, Abdallá, censal en 1408.

FACEN su yerno, morabatín de 1404 .

FAIUBA, Abrafim, censal en 1408.

FAYUBET, en 1408 compró un patio o corral por 40 sueldos a Zoayr.

FUDEYL, Yaye, morabatín de 1404; besante de 1408. También Fudiel.

FULEY, Coot, morabatín de 1404; censal en 1408.

GANANERI, Caat, de la Vall de Seta. En 1416 vendió a Caat Bacora, de Ondara, unas casas por 14 libras y 15 sueldos.

GEBELLI, Cilim, morabatín de 1404; besante de 1408. Tenía una hija que se cita en el morabatín de 1404.

GEHMI, Mahomet, citado en 1416 en una venta de tierra, era dueño de un campo.

HAJUBA, Mahomat, besante de 1408.

HAJUBA, la mujer de, morabatín de 1404.

HALIL, Caat, en 1408 vendió un higueral pequeño (figueralet) a Abdallá Nadir por 7 sueldos y 6 dineros. En 1416 poseía un higueral.

HAMER, Geme, en 1416 se cita una viña suya en un deslinde de propiedad, en la venta de una viña de Ramón Pelegrí a Cayt Zintar.

HATAP, Abdallá, morabatín de 1404.

HAYR, Cayt, morabatín de 1404; censal en 1408. Tenía un hijo que ese año pagó al señor 7 sueldos, 6 dineros por el tercio del salario de los juglares en sus bodas, que hizo ese año en Ondara.

HAYZOPARA, morabatín de 1404.

HIAYHE, fabricante de peines. En 1416 compró de Pere Martí, de Ondara, un trozo de tierra por 2 libras, 5 sueldos.

HIAYHE, herrero, citado en 1416 como dueño de una viña, que lindaba con otra de Pere Martí, y otra de Joan Gençor.

HOAYMET, Mahomat, besante de 1408, censal.

HOAYMET, Yayeix, herrero, citado en el besante de 1408. Yaye Redovà le vendió un trozo de tierra en la huerta de Ondara por 17 libras y 2 sueldos.

JAYENI, Mahomat, o Jeyeni, Jehiní. Morabatín de 1404; besante de 1408. Fue castigado con 45 azotes por decir palabras injuriosas, y conmutada la pena por una multa de 22 sueldos. Ese año vendió un trozo de tierra a Joan Cardona por 70 sueldos. Citado en 1416 en la venta de un censal de 4 dineros a Francesc Dalmau, notario de Gandía, por 20 libras. 
JUBET, Mahomet, en 1416 compró un trozo de tierra que le vendió Ramón Lombart, presbítero, por 6 libras.

LOPPO, Abrafim, fabricante de peines, besante de 1408.

MAHOMAT, "lo pellero", en 1416 compró un trozo de tierra plantado de viña a Hiayhe Alcocer por 4 libras y 8 sueldos. Ese año vendió a Huaylis Maxato una casa por 12 libras. También vendió un trozo de tierra a Mahomat Bacorapor por 15 libras.

MALICH, Azmet, morabatín de 1404, citándose en otro fuego su sobrino; besante de 1408, censal.

MARCHIQUA, viuda, besante de 1408 .

MAUHIA, Cale, besante de 1408. En 1416 sabemos que poseía una viña en el término, que lindaba con tierra de Melich y caminos.

MAUAGÜF, Azmet, 1408.

MAXATO, Huayhie, en 1416 compró unas casas que le vendió Mahomat Lopello por 12 libras.

MAYORQUÍ, Azmet, censal en 1408.

MAZERANO, Geme, besante de 1408.

MEGUECH, morabatín de 1404.

MELICH, citado en una delimitación de propiedad tras una venta de un trozo de viña de Ramón Lombart, presbítero. Poseía un trozo de tierra.

MICHICHI, Mahomat, o Mechini, censal en 1408. En 1416 se le cita en un deslinde de propiedad como poseedor de tierra, junto al río de Ondara y la acequia del molino d'En Coll. Podría ser el personaje que aparece con la grafía Miqiqo, que poseía un higueral ese año.

MOCHTA, Alí, morabatín de 1404; besante de 1408, censal.

MONDOLL, Cayt, de Pinela. En 1416 compró un trozo de tierra por 10 libras a Azmet Amdi, de Elk Verger.

MORABIT, Mahomat, morabatín de 1404.

MORIT, Mahomat, alias Mahomat Ell, besante de 1408. Quizá fuera el Mahomat Morabit arriba citado en 1404.

MORRACHO, Caat, juglar, morabatín de 1404; censal en 1408.

MUÇA, morabatín de 1404. Un tal Muça poseía un higueral en 1416.

MUÇA, Azmet, besante de 1408, censal.

MUNDO, Mahomat, Se le cita en 1408 como de la Vall d'Exaló (Jalón) y paga besante como extranjero (estrany) al haberse hecho vasallo del duque.

MUZEYT, Abdallá, citado en 1416 como testigo en la venta de un trozo de tierra de riego a Azmet Benzaber.

NADIR, Abdallá. Se cita su mujer en el morabatín de 1404; besante de 1408, censal. Tenía un hijo, que en 1408 fue condenado por sospechoso de robo, junto 
con Mahomat Alcácer y el hijo de Baqua, siendo condenados a 33 sueldos de multa. Compró un higueral pequeño por 7 sueldos y 6 dineros a Halil.

NADIR, Caat, morabatín de 1404. Se le cita como dueño de tierra en una delimitación de propiedad en la venta de tierra que Hiayhe Alcocer hizo a Miquel Pérez.

NAYAR, Yaye, besante de 1408, censal.

NOCORON, vid. Noçorón.

NOÇORÓN, Axer, morabatín de 1404; besante de 1408, censal.

NOÇORÓN, Cayt, censal en 1408. Se cita una tierra suya en 1416 en un deslinde de propiedad en la venta de una viña de Azmet Alaret, con la que lindaba.

NOÇORÓN, Mahomat, citado como testigo en la venta de un trozo de tierra por Azmet Alchatan. Un Mahomat Nocorero aparece como testigo ese año en otra venta, y quizá fuera el mismo personaje.

OZMÉN, vid Uzmén.

PARRELL, Azmet, alias Lopello. En 1416 vendió a Azmet Zacal una casa.

PARRELL, Mahomet, alias Lopello, pariente de Azmet en grado que desconocemos y que llevaba su mismo alias. Citado en 1416 en la venta de un trozo de viña a Miquel Pérez, hostalero de Ondara, por 6 libras y 12 sueldos.

PARRI, Cacic, citado en un deslinde de tierras de 1416, poseía un campo de "terra".

PAZOÇ, Azmet, morabatín de 1404; besante de 1408.

POLLERO, Mahomet lo, en 1416 compró un trozo de tierra en la huerta del lugar a Cayt Zaydón por 11 sueldos.

RACLU, Caat, citado en 1416 como testigo en la venta de un huertecito del alfaquí Rodová.

RAÇBAYDA, Alí, morabatín de 1404; besante de 1408, censal.

RAFE, Azmet, morabatín de 1404; besante de 1408, censal. En 1416 poseía un higueral.

RAFE, Cilim, o Raffe. Besante de 1408, censal. Abonó al duque de Gandía 7 sueldos, 6 dineros por el derecho de las bodas que hizo en Ondara ese año. En 1416 compró un trozo de tierra de secano a Mahomet Benzuqueya por 260 sueldos.

RAFE, Coot, morabatín de 1404; besante de 1408, censal. Un Caat Raffe compró un trozo de tierra de secano en 1416 a Azmet Alchatan por 20 libras.

RARO, Ali, morabatín de 1404; besante de 1408, censal.

RATLU, Caat, censal en 1408.

RAZBAYDA, Azmet, En 1416 se le cita en un deslinde de propiedad, indicando que tenía "tierra".

RAZBAYDA, Cilim, en 1416 se cita como dueño de una viña en un deslinde de propiedad en la venta que Alí Alagraz hizo de un trozo de tierra. 
REDOVA, Yaye, vendió en 1408 un trozo de tierra e higueral a Yaye Alcácerpor 56 sueldos. También otro trozo de tierra en la huerta de Ondara a Yaye Ayayeix Hoaymet, herrero, por 17 libras, 2 sueldos. En 1416 se cita un Rodovà, alfaquí, que pudiera ser la misma persona. Compró un "carreró" a Azmet Hamer por 6 sueldos, y una viña a Azmet Aloret por 2 libras y 5 sueldos.

RODOVÁ, alfaquí. En 1416 vendió un huertecito a Azmet Benzaber por 11 sueldos. Compró una viña de Azmet Aloret por 2 libras y 5 sueldos.

TAIX, Yaye, o Caix. Morabatín de 1404; besante de 1408, censal. Poseía tierra, citada en un deslinde de 1416 por la venta de un trozo de tierra de Ramón Pelegrí, con la que lindaba. También poseía una viña, que lindaba con la de Cilim Razbayda y una senda.

TARANDO, Amar, censal en 1408. Podría ser Taradero, ya que el signo de abreviatura cubre toda la palabra (Tarado).

TAER, Hiayhe, citado en 1416 en una delimitación de tierras, citándose tierras suyas.

THAER, Fondell, morabatín de 1404; censal en 1408.

TAHER, Hamdim, en 1416 poseía un higueral.

TINA, viuda, besante de 1408 .

UHAYMET, Yayeix, alias Mesquiquo, besante de 1408 .

UZMEN, Caat, u Ozmén. Besante de 1408, censal. En 1416 se cita una tierra suya en un deslinde de propiedad. Poseía un higueral.

VALENA, Fumeyt, besante de 1408.

VALENÇI, Fumeyt, besante de 1408.

XADIT, Axer, morabatín de 1404; besante de 1408.

XADIT, Cilim, censal en 1408.

XADIT, Coot, en 1416 compró la mitad de la casa de Caat Acet por 3 libras.

XADIT, Mahomat, morabatín de 1404; besante de 1408. En 1416 poseía un higueral.

XAGHA, morabatín de 1404 .

XIXONÍ, Azmet, o Xexoní. Censal en 1408. En 1416 se le califica residente en Pamíes y firma como testigo en la venta de un trozo de tierra.

XOAYA, Caat, morabatín de 1404; censal en 1408. Su hijo fue condenado ese año por el baile a una multa de 11 sueldos por haber sacado el cuchillo contra un converso.

XOAYF, Calim, besante de 1408. También Xuayf.

XUHAYA, Caat, besante de 1408.

XUAYA, Cilim, morabatín de 1404; besante de 1408, censal. También como Xoaya.

XUQUEYHEC, Galip, de Matosses. En 1416 compró a Joan García, de Denia, un trozo de tierra por 22 libras. 
ZACAL, citado en 1416 en la venta de unas casas de Caat Gananeri, de la Vall de Seta.

ZALE, vid. Çale.

ZAYDO, Abrafim, morabatín de 1404; besante de 1408. También Zaydón.

ZAYDO, Coot, morabatín de 1404, citándose su sobrino como otra unidad familiar diferente; besante de 1408 .

ZAYDO, Cayt, en 1416 vendió a Mahomet lo Pollero un trozo de tierra en la huerta por 11 sueldos.

ZAYDO, Çaat, besante de 1408.

ZAYDÓ, Yayeix, citado en el morabatín de 1404 como Yacix Zaydón; besante de 1408.

ZAYDÓN, vid. Zaydó.

ZEBELI, Alí, en 1416 poseía una viña, citada en un deslinde de tierras de una venta de una viña de Ramón Pelegrí a Cayt Zintar.

ZICH ZICH, Jucef, morabatín de 1404; besante de 1408.

ZIMAR, Cayt, en 1416 vendió un trozo de viña a Alí Alchagar.

ZINTAR, Cayt, citado en 1416 como testigo en la venta de unas casas de Caat Gananeri, de la Vall de Seta. Poseía una viña en el término de la localidad. Compró a Joan Pelegrí, procurador de Ramón Pelegrí, de Valencia, una viña por 8 libras y 3 sueldos.

ZOAYR, viuda, una persona con este nombre aparece en el morabatín de 1404; besante de 1408 .

ZOAYR, censal en 1408.

ZOAYR, 1408. Un individuo con este nombre vendió un patio o corral a Fajubet por 40 sueldos.

\section{CRISTIANOS}

AYMERICH, Nicolau, pagaba 4 sueldos de censos por casas en 1408.

BONANAT, Guillem, pagaba en 14083 sueldos por una viña acensada.

BONET, Ramón, pagaba 4 sueldos de censos por casas en 1408.

BOYL, Pere, sastre, pagaba 4 sueldos de censos por casas en 1408.

CAPELLÀ, lo, pagaba 4 sueldos de censos por casas en 1408 y 12 sueldos por viñas y huerto.

CARDONA, Joan, pagaba 4 sueldos de censos por casas en 1408 y 18 sueldos por obrador y viña.

CORELLA, Rodrigo de, pagaba 4 sueldos de censos por casas en 1408.

ESTEVE, Pere, la mujer de, morabatín de 1404. 
FEBRER, Domingo, morabatín de 1404. Pagaba 15 sueldos de censos por casas en 1408.

FERRADA, Jaime, morabatín de 1404.

FORT, Pere, sastre. En 1408 pagaba 2 sueldos por una viña acensada.

GARCÍA, Joan, morabatín de 1404. Su suegra aparece como otra unidad familiar aparte. Pagaba 4 sueldos de censos por casas en 1408 y otros 23 por viñas, tierras y huertos. Un Joan García, habitante en Denia, que no sabemos si era la misma persona, vendió en 1416 un trozo de tierra de riego a Azmet ben Zeber, moro de Ondara por 14 libras.

GAVILA, Arnau, morabatín de 1404. Pagaba 4 sueldos de censos por casas en 1408. Este año se le califica de "menor" y tenía acensados un molino, casas y tierra por 38 sueldos y 9 dineros.

GAVILA, Bernat, pagaba 4 sueldos de censos por casas en 1408.

GAVILA, Gonzalo, morabatín de 1404.

GAVILA, Guillem, pagaba 4 sueldos de censos por casas en 1408 y 7 sueldos por viñas y tierras acensadas.

GENÇOR, Joan, morabatín de 1404. Pagaba 4 sueldos de censos por casas en 1408 , y otros 20 por viñas y tierras.

GENÇOR, Manuel, pagaba 4 sueldos de censos por casas en 1408.

JOAN, Bernat, carpintero de Denia, citado como testigo en la venta de un trozo de tierra de riego de Joan García, de Denia, en el término de Ondara.

JORNETA, Na, morabatín de 1404 . Se cita a su hijo como otro morabatín independiente.

MARTÍ, Pere, morabatín de 1404. Pagaba 4 sueldos por censo de casa en 1408.

MARTÍ, Pere, su hijo, morabatín de 1404.

MIR, Francesc, morabatín de 1404.

MULET, Jaime, la mujer de, morabatín de 1404. Ella y sus hijos pagaban 4 sueldos de censos por casas en 1408 .

MULET, Joan, en 1408 pagaba 7 sueldos por unas viñas acensadas.

ORTONEDA, Berenguer d', en 1408 pagaba 8 sueldos por casas que tenía a censo.

ORTONEDA, Roger, morabatín de 1404. Se cita pagando el impuesto aparte a la "dona que te en sa casa", que no sería su mujer, es evidente.

ORTOLÀ, En, tejedor, morabatín de 1404.

PALAU, Francesc, en 1408 pagaba al señor 6 sueldos por una viña acensada.

PASTOR, Domingo, pagaba 5 sueldos de censos por casas en 1408.

PASTOR, Gonzalo, morabatín de 1404.

PELEGRÍ, Guillem, morabatín de 1404. Tenía casas, tierras y viñas acensadas en 1408. 
PELEGRÍ, Joan, pagaba 1 sueldo de censos por casas en 1408.

PELEGRÍ, Pere, morabatín de 1404. Pagaba 4 sueldos de censos por casas en 1408. Tenía acensadas tierras y viñas.

PELEGRÍ, Ramón, morabatín de 1404. Pagaba 4 sueldos de censos por casas en 1408 y otros 6 por viñas y tierras.

PERIC, Ferrando, o Pérez, morabatín de 1404. Pagaba 4 sueldos de censos por casas en 1408.

PLA, Na, morabatín de 1404. Sería el Antoni Pla, que en 1408 pagaba 15 sueldos por censo de unas casas.

RAMONA, Na, morabatín de 1404. Se cita también como unidad familiar independiente a su hijo, y en otra diferente su nieta.

ROIÇ, Jaime, morabatín de 1404 . Se cita a su hijo como otra unidad familiar propia.

SALVADOR, Ramón, pagaba 4 sueldos de censos por casas en 1408 y 25 sueldos por el horno del lugar.

SANCHEZ, Joan, en 1408 tenía acensada tierra.

SÁNCHEZ, Joan, los hijos de, pagaban al señor 550 sueldos en 1408 por la taberna y el hostal, acensado a perpetuidad.

VENRELL, Arnau, pagaba 4 sueldos de censos por casas en 1408.

VIDAL, Bernat, sastre, morabatín de 1404.

VIDAL, Ramón, morabatín de 1404.

\section{RESUMEN}

A partir de un cabreve de 1416 conservado en el Archivo del Reino de Valencia hemos pretendido reconstruir cuál fue el desarrollo del lugar de Ondara, en el norte de la actual provincia de Alicante, en particular la renta percibida por el señor, el duque de Gandía. Ondara tenía una población de mayoría mudéjar, aunque también vivían en la localidad cristianos. De esta renta era la partición de frutos de los mudéjares y los cristianos, con sus 4.000 sueldos, la que proporcionaba los mayores ingresos en las arcas señoriales, es decir, el gravamen sobre la actividad económica de la localidad, seguida por los arrendamientos y el besante. Además de la agricultura había una actividad artesana en torno a la cantarería, la fabricación de jabón y el tinte. Se completa el estudio con unas normas municipales del año 1410 y la prosopografía de los vecinos.

Palabras clave: mudéjares, Ondara, Alicante, renta feudal, señoríos, agricultura, demografía, prosopografía. 


\section{ABSTRACT}

Obtained from a document of 1416 preserved in the Archive of the Kingdom of Valencia, we have pretended to rebuild the Ondara's place of development, in the north of Alicante's province, particularly the rent received by the lord, the Duke of Gandia. Ondara had a population of Mudejar majority, even though Christians also lived in the locality. From this rent it was the partition of fruits from the Mudejares and Christians, with their 4000 salaries, the one that produced the most incomes in the lord's arks; this was the tax over the economical activity in the locality, followed by the leasing and the besante. Apart from the agriculture there was an artisan's activity related with pottery, the manufacture of soap and dye. The study is completed with some municipal laws from the year 1410 and the prosopography of the neighbours.

Key words: mudejares, Ondara, Alicante, feudal rent, manor, agriculture, demography, prosopography. 